Resumo

\title{
Alteração do estado de humor em atletas da Seleção Brasileira Militar de futebol na temporada 2015
}

Mario Yoshiro Kasai Bsci, Ângela Nogueira Neves PhD

Introdução: Podemos encontrar na literatura trabalhos tratando sobre a relação da alteração do estado de humor e overtraining em atletas. Porém há poucas pesquisas que trazem essa associação na modalidade futebol; e, especificamente, na Seleção Brasileira Militar, não há nenhum.

Objetivo: Assim, o presente estudo buscou, primeiramente, a relação da alteração dos estados de humor e estresse. Em um segundo momento, investigou se há variância do escore do estado de humor de acordo com a posição do jogador em campo.

Métodos: Fizeram parte desta pesquisa 31 atletas que responderam duas escalas (BRUMSe REST-Q) e um questionário demográfico. Foi aplicado um teste de normalidade de Shapiro Wilk, em seguida um teste de correlação de Spearman e uma análise de variância de Kruskal-Wallis.

Resultados: A amostra tem o perfil de iceberg invertido no estado de humor. Observou-se a correlação entre os escores da BRUMS e as escalas da REST-Q. Não há variação do estado de humor em função da posição de campo nessa amostra.

Conclusão: Os resultados confirmam a hipótese inicial de haver relação entre estado de humor e a percepção subjetiva de estresse nos atletas da Seleção Brasileira Militar de Futebol. A segunda hipótese, de que haveria variação dos escores dos estados de humor de acordo com a posição de cada jogador em campo, foi refutada. 